\title{
EARLY REHABILITATION AFTER CORONARY ARTERY BYPASS GRAFTING: LIMITATIONS AND PROSPECTS
}

\author{
A.A. INOZEMTSEVA ${ }^{1,2}$, Y.A. ARGUNOVA', S.A. POMESHKINA' \\ 'Federal State Budgetary Institution «Research Institute for Complex Issues of Cardiovascular Diseases», Kemerovo, Russia \\ ${ }^{2}$ Federal State Budgetary Educational Institution of Higher Education "Kemerovo State Medical University" the Ministry of \\ Healthcare of the Russian Federation, Kemerovo, Russia
}

\begin{abstract}
The number of patients undergoing coronary artery bypass grafting is increasing over the past decade. Therefore, cardiac rehabilitation following CABG is gaining new relevance. Advanced cardiac rehabilitation program following CABG includes three phases. Phase I of cardiac rehabilitation is an initial in-hospital phase, which all patients undergo after surgery. However,
\end{abstract}

there is no single Phase 1 cardiac rehabilitation program recommended for patients following CABG in the in-hospital settings. This review presents an analysis of existing Russian, European and American data on effectiveness and safety of early rehabilitation in patients after CABG in the in-hospital settings.

Keywords: rehabilitation, coronary artery bypass grafting, fast-track, exercise training.

For citation: Inozemtseva A.A., Argunova Y.A., Pomeshkina S.A. Early rehabilitation after coronary artery bypass grafting: limitations and prospects Complex Issues of Cardiovascular Diseases. 2017;6(4):129-132. (In Russ.) DOI:10.17802/2306-1278-2017-6-4-129-132

The steady increase in the number of patients with coronary artery disease (CAD) undergoing open-heart surgeries necessitates the development and implementation of postoperative cardiac rehabilitation programs. The vast majority of patients referred to cardiac rehabilitation are eligible to undergo this program [1]. However, there is a lack of optimal cardiac rehabilitation programs to restore patients following myocardial revascularization in both specialized centers for cardiovascular surgeries and in the departments of cardiology. The World Health Organization defines cardiac rehabilitation as the sum of the activities required to favorably influence both the subjacent cause of the disease and the physical, mental and social conditions of the patient. Improvements in rehabilitation programs for patients after $C A B G$ are of particular medical and clinical significance [2].

The introduction of cardiac rehabilitation program is of significance importance from an economic point of view since it reduces public health expenditure by shortening the length of stay in hospitals and decreasing the rate of repeated hospitalizations [3].

Unfortunately, the main approaches to cardiac rehabilitation are still based on scientific evidence of the effectiveness and safety of rehabilitation programs for patients after acute coronary events.

Cardiac rehabilitation programs for patients undergoing heart reconstruction surgeries are becoming more relevant in today's cardiology, physical medicine and rehabilitation. Many aspects of these programs have not been studied yet [1]. The previous experience of rehabilitation measures to restore patients after myocardial infarction as well as available evidence on the mechanisms of action of physical factors allowed developing a 3-phase cardiac rehabilitation program for patients after CABG [4]. However, the direct transition of rehabilitation methods for patients after myocardial infarction to patients after cardiac surgery may be confusing. Surgical treatment is associated with a number of factors that should be taken into account while developing cardiac rehabilitation program: e.g. cardiopulmonary bypass, perioperative psychoemotional distress and surgical intervention itself.

A large number of studies have been devoted to optimizing cardiac rehabilitation programs in the developed countries. However, it is rather challenging in the Russian Federation. New insights in cardiac rehabilitation were presented in the first Russian guidelines "Coronary Artery Bypass Grafting in CAD Patients: Rehabilitation and Secondary Prevention" (2016). This is the first statement accumulating present medical knowledge and presenting optimal rehabilitation program for patients [4].

Advanced cardiac rehabilitation program consists of three phases: Phase 1 - in-hospital rehabilitation, Phase 2 - monitored exercise and education classes, and Phase 3 - supervised maintenance exercise group in the outpatient settings. Successful medical rehabilitation depends on the following core principles: early beginning, consistency of care, continuity of care during all rehabilitation phases, integrated and individual approach. Integrated care pathways provide secure and adequate exercise trainings, psychological sessions and trainings and other methods of non-medical therapy. However, none Russian medical protocol of care contain this information. 
The Order of the Ministry of Healthcare of the Russian Federation № 1705H of December 29, 2012 approved core principles for organizing medical rehabilitation, which partially solves the above-mentioned issues. However, this Order is mainly focused on the implementation of the outpatient rehabilitation. Phase 1 in-hospital rehabilitation is briefly discussed in clause 7 of this Order, suggesting that it should take place while the patient in the intensive care recovering from acute event according to the profile of the underlying disease and has confirmed rehabilitation potential without any contraindications for selected rehabilitation methods. This definition does not contain clear and definite description of the activities that may be used for early patient rehabilitation. In addition, the timely implementation of this standard of care is delayed by a number of organizational problems. The majority of the rehabilitations measures can not be used for all patients, due to the lack of equipment or qualified personnel. This problem is more critical for patients living in rural areas. Moreover, not all urban areas have a specialized rehabilitation center and not all medical centers have separate rehabilitation departments with modern equipment. Financial support and extra funding of these programs are still being discussed, and the issue has not been completely resolved.

The majority of medical centers may provide only Phase 1 in-hospital rehabilitation for patients after myocardial infarction and open-heart surgeries. Rehabilitation methods used during this phase are limited and mainly include early mobilization to prevent the deleterious effects of bed rest. Thus, patients commonly develop stage II physical activity and rarely stage III (walking in the wards, halls, etc.) during this rehabilitation phase. Therefore, patients who are not ready for basic self-care at discharge from the hospital are transferred to outpatient rehabilitation. This phase incorporates a combination of supportive counseling and determines the strategies for a long-term, almost lifelong secondary prevention. Unfortunately, this critical rehabilitation phase is replaced by low effective outpatient supervision, provided by general physicians and cardiologists. Special education for patients who have undergone open-heart surgery and their relatives, containing separate modules for exercise training, psychological adaptation, and the modification of risk factors, is quite rarely used in today's clinical practice [1]. Thus, according to the existing conditions in Russia, the only $100 \%$ feasible phase of rehabilitation is in-hospital one. Therefore, it appears to be relevant to design and introduce an early rehabilitation program for in-hospital settings.

Since 2004, the ACC / ANA guidelines stated the priority of the fast-track rehabilitation of patients who underwent CABG [5]. Reducing length of the inpatient postoperative treatment and using a differentiated approach to the selection of patients for inclusion in the fast-track rehabilitation is not associated with increased mortality, morbidity or the high of repeated hospitalizations. Importantly, increasing length of hospitalization does not allow improving these indicators [6]. The most important components of fast-track rehabilitation of patients after CABG include an optimization of anesthetic support for early patient extubation and shortening the length of stay in the intensive care unit; prevention of heart rhythm disturbances; availability of short-term follow-up after hospital discharge.

Exercise trainings after CABG are a key activity in the cardiac rehabilitation programs, as they help to improve the prognosis, increase exercise tolerance and improve the quality of life. Determining the optimal timing of the beginning of exercise training is an important issue to discuss.

Early mobilization of patients from the first day after surgery who have no complications in the intraoperative and postoperative period is one of the main principles of rehabilitation, able to prevent the most common manifestations of prolonged hypokinesia, such as bronchopulmonary complications, orthostatic hypotension and tachycardia are the [7]. All complications may prolong the length of stay in the intensive care units, resulting in preserved hypokinesia [8]. Hypokinesia is known to cause decreased protein synthesis, activation of proteolytic pathways, resulting in large decreases in muscle mass and strength and diminished ability to perform daily functional activity [9]. In addition, the harmful effects of hypokinesia may eventually be generated and last for months and even years after CABG [10].

According to the international medical literature, the effectiveness and safety of early exercises for patients undergoing CABG have been already proved in [11]. Early exercise trainings are associated with low rate of respiratory complications after open-heart surgery [12], decreased loss of patients' muscle mass [13], and low rate of postoperative cognitive dysfunction [14]. J. Fell and et al. compared patient undergoing fast track physical rehabilitation (0-28 days) and patients who were referred to exercise training 28 days after CABG. They found that exercise trainings initiated in the first hours after surgery provided a higher level of exercise tolerance among patients after CABG, whereas delayed rehabilitation did not have any beneficial effects. They concluded that fast track rehabilitation should be initiated in the first hours after CABG and is an obligatory element of cardiac rehabilitation programs [15].

Hojoskov I.E. et al. developed a fast track cardiac rehabilitation program in the SheppHeartCABG trial. Patients are early mobilized and engaged to walk for 5 minutes twice a day with a gradual increase in the duration of walking sessions and their number. Patients who are eligible for further trainings are referred to 10-minutes cycling trainings on day 3 after CABG. Physical activity intensity is assessed with The Borg Rating of Perceived Exertion (RPE). In addition, patients are taught respiratory exercises and breathing techniques from the beginning of Phase 1 rehabilitation. This cardiac rehabilitation program has been successfully implemented in more than 10 European cardiac centers [16]. 
D. Karaszewcki et al. found that early rehabilitation after CABG, including early 'verticalization' of the heart, controlled walking in a straight line or walking the ladders (3-4 days after surgery), leads to increased patient fitness and decreased resting heart rate compared with patients undergoing conventional rehabilitation [17].

Mendes R.G. et al. proved that early rehabilitation initiated from the first day after CABG may reduce postoperative hyperactivity of the autonomic nervous system, both in patients with normal and reduced left ventricular function [18].

D. Da Costa Torres et al. found that early rehabilitation, including early initiation of cycling trainings, results in an increase in the distance of the six-minute walking test and reduces the number of respiratory complications compared with conventional rehabilitation [19].

Early rehabilitation after CABG is rather effective in patients with complications. Thus, Zehua Dong et al. compared two groups of patients, who were on prolonged (more than 72 hours) ventilation after CABG. Group 1 patients were engaged in exercises trainings already in the intensive care unit (sitting in bed, sitting on the edge of the bed, sitting on a chair and 'verticalization' of the heart). The control group started to perform the exercises after switching to spontaneous breathing and transferring to the Department of Cardiac Surgery. Researchers have shown that early physical rehabilitation is cost effective and contributes to a faster recovery and early switching to spontaneous breathing as well as allows reducing both the length of stay in the intensive care unit and the length of in-hospital stay [20].

Despite available international experience of fast track rehabilitation, there is a limited number of studies on cardiac rehabilitation in Russia, starting on days 10-21 after CABG. Thus, Petrunina L.V. enrolled 545 patients after $C A B G$ to individual exercise trainings with individual physical activity intensity. Phase 1 rehabilitation started on days 18-21 after surgery. In addition to exercise training, all patients received a combination of supportive counselling and education. This cardiac rehabilitation program allowed improving the clinical effect of the surgery and facilitate patients' returning to work (RTW)[21].

Bazylev V.V. and Galtseva N.V. referred 109 patients with preserved left ventricular systolic function after CABG to controlled treadmill exercises of light intensity (3-6 MET) started from 3-4 days after CABG. Accurate monitoring of blood pressure, heart rate, ECG control were perform to ensure the safety of the program. Fast track rehabilitation resulted in a decrease in the average in-hospital stay and improved physical and mental components according to the SF-36 questionnaire. Moreover, early exercise trainings did not cause cardiovascular events, wound complications and significant changes in hemodynamic parameters [22].

Lubinskaya E.I. et al. found that patients who underwent multidisciplinary rehabilitation on days 8-17 after CABG, including exercise trainings, psychological sessions and education are more compliant with the further rehabilitation phases and demonstrated fewer cardiovascular events in the 2-years follow-up [23].

Ganenko O.S. et al. found that the early mobilization and exercises on days 10-12 after CABG increases exercise tolerance and improves psychological and emotional well-being [24].

Previous studies conducted at the Research Institute for Complex Problems of Cardiovascular Disease reported that initiation of exercise trainings on day 14 after CABG can improve a number of homeostasis parameters. Cardiac rehabilitation have positive impact on NO metabolites, endothelium-1, total peroxide concentration, indices of endothelium-dependent vasodilation, contributing to the improvements of the functional state of the endothelium, increased vasodilation and decreased vasoconstriction [25].

Kuular A.A. et al. demonstrated that cycling training on day 10 after CABG reduces blood lactate levels and improves the spirograms (FEV1/ FVC ratio) [26]. The main argument that limits the introduction of fast track rehabilitation in Russia is the view that exercise trainings affect the postoperative wound healing by reducing the rate of its regeneration and contributing to the development of surgical complications. This misbelieve results in patients' low compliance with exercise trainings and low physical activity intensity [27]. However, some researchers did not found any significant differences while assessing the impact of early rehabilitation on postoperative sutures [17, 22, 28]. Moreover, the number of international and national studies proved that early cardiac rehabilitation is safe and does not provoke any cardiovascular and pulmonary complications $[15,16,22$, $29,30]$.

However, the data obtained in European and American studies can not be blindly extrapolated to the Russian patients. They commonly have poor adherence to treatment and do not adopt healthy lifestyle as well. They have lack of regular physical activity, which worsens by unwillingness to attend trainings and education session in Phase 1 in-hospital rehabilitation [31]. Researchers and cardiologists have to solve this important problem in today's cardiology. They have to develop and implement effective and safe cardiac rehabilitation program for patients after CABG adapted to the Russian environment. Definite answers should be obtained about optimal timing of early exercise trainings, their intensity, frequency and duration during Phase 1 in-hospital rehabilitation of patients following CABG.

Recently, significant progress has been made in the rehabilitation of patients following CABG. Unfortunately, this success is achieved by the implementation of rehabilitation Phases 2 and 3, bypassing Phase 1. Therefore, cardiologists and rehabilitation specialists should focus on the development of early rehabilitation programs. However, it should be noted that Phase 1 in-hospital rehabilitation is a part of multicomponent cardiac rehabilitation, which will be ineffective in the absence of continuity of care between all stages. 


\section{REFERENCES}

1. Apонов Aronov D.M., Bubnova M.G. Challenges of the implementation of a new cardiac rehabilitation system in Russia. Russian Journal of Cardiology. 2013;(4):14-22 DOI:10.15829/1560-40712013-4-14-22. (In Russ.)

2. Pomeshkina S.A., Kondrikova N.V., Barbarash O.L. Labour ability assessment of patients undergone coronary artery bypass grafting. Complex Issues of Cardiovascular Diseases. 2014;(1):26-30. (In Russ.) DOI:10.17802/2306-1278-2014-1-26-30

3. Brugemann J., Gerds-Ploeger H.Z. A new incentive for cardiac rehabilitation. Ned.Tijdschr.Geneeskd. 2015;159:94-99.

4. Bokeria L.A., Aronov D.M. Koronarnoe shuntirovanie bolnih EBS: reabilitathia I vtoricnaya pofilaktika. Rossiiskie klinicheskie recomendatsii. Moscow; 2016 (in Russ).

5. Eagle K.A., Guyton R.A., Davidoff R., Edwards F.H., Ewy G.A., Gardner T.J., et. al. ACC/AHA 2004 guideline update for coronary artery bypass graft surgery: a report of the American College of Cardiology/ American Heart Association Task Force on Practice Guidelines (Committee to Update the 1999 Guidelines for Coronary Artery Bypass Graft Surgery). Circulation. 2004; 5(14):340-437.

6. Watanabe G. Medical care issues in Japan highlighted by the regulatory approval of the da Vinci Surgical System. Surg. Today. 2011; 41(9):1182-1183.

7. Hillis L.D., Smith P.K., Anderson J.L., Bittl J.A., Bridges C.R., Byrne J.G. et al. ACCF/AHA guideline for coronary artery bypass graft surgery: executivesummary: a report of the American College of Cardiology Foundation/American Heart Association Task Force on practice guidelines. Circulation. 2011; 124: 2610-2642.

8. Iaizo A., Delgado F.E., Rocha G.M. Complications that increase the time of hospitalization at ICU of patients submitted to cardiac surgery. RevBrasCirCardiovasc. 2010; 25(2): 166-171.

9. Coker R.H., Hays N.P., Williams R.H. Bed rest promotes reductions in walking speed, functional parameters, and aerobic fitness in older, healthy adults. JGerontol. A. Biol. Sci. Med. Sci. 2015; 70(17): 91-96.

10. Truong A.D., Fan E., Brower R.G., Needham D.M.Bench-tobedsidereview: mobilizing patients in the intensive care unit-from pathophysiology to clinical trials. Crit. Care. 2009; 13(4):21-26.

11. Galve E., Castro A., Cordero A., Dalmau R., Facila L. Update in cardiology: vascular risk and cardiac rehabilitation. Rev. Esp. Cardiol. 2013;66(2): 124-130.

12. Borghi-Silva A., MendesR. G., Costa F.D.S.The influences of positive end expiratory pressure (PEEP) associated with physiotherapy intervention in phase I cardiac rehabilitation. Clinics. 2005; 60(6): 465472 .

13. Balady G.J., Ades P.A., Bittner V.A., Franklin B.A., Gordon N.F., Thomas R.J. et al. Referral, enrollment, and delivery of cardiac rehabilitation/secondary prevention programs at clinical centers and beyond: a presidential advisoryfrom the American Heart Association. Circulation. 2011; 124(25): 2951-2960.

14. Brummel N.E., Jackson J.C., Girard T.D.,Pandharipande P.P., Schiro E., Work B. et al. A combined early cognitive and physical rehabilitation program for people who are critically ill: the activity and cognitive therapy in the intensive care unit (ACT-ICU) trial. Phys. Ther. 2012; 92(12):1580-1592.

15. Fell I., Dale V., Doherty P. Does the timing of cardiac rehabilitation impact fitness outcomes? An observational analysis. Open Heart. 2016; 3(1): 24-33.

16. Hojskov I.E, Moons P., Hansen N., Soren La Cour, Olsen P.,Gluud C. et al. SheppHeartCABG trial-comprehensive early rehabilitation after coronary artery bypass grafting: a protocol for a randomised clinical trial. BMJ Open. 2017; 7(1): 2040-2053.

17. Karaszewski D. Comparison of two models of hospital rehabilitation in patients after coronary artery bypass grafting. Kardiochir.Torakochirurgia Pol. 2014; 11(1): 86-89.

\section{Conflict of interest:}

The authors have no financial disclosures or conflicts of interest. Funding:

This exploratory research was supported by the Federal Agency of Scientific Organizations.
18. Mendes R.G., Simoes R.P., Costa F. de S., Pantoni C.B., Di Thommazo-Luporini L., Luzzi S., et al. Is applying the same exercisebased inpatient program to normal and reduced left ventricular function patients the best strategy after coronary surgery? A focus on autonomic cardiac response. Disabil.Rehabil. 2014;36(2):155-162.

19. Daniel da Costa Torres, Priscila Maria Ramos dos Santos, Helder José Lima Reis, Denise Moraes Paisani, Luciana Dias Chiavegato. Effectiveness of an early mobilization program on functional capacity after coronary artery bypass surgery: A randomized controlled trial protocol. SAGE Open Medicine. 2017;4: 1-8.

20. Zehua Dong, Bangxu Yu, Quanfang Zhang, Haitao Pei, Jinyan Xing, Wei Fang, et al. Early rehabilitation therapy is beneficial for patientswith prolonged mechanical ventilation aftercoronary artery bypass surgery. Int. Heart J. 2016;57(2):241-246.

21. Petrynina L.V., Malikov V.E. Stacionarniyi etap bolnih EBS posle operacii aorto-coronarnogo shuntirovaniya. Bulleten NCSSH im. A.N. Bakyleva RAMN serdechno-sosydistie zabolevaniya. 2015; 16: 166171 (in Russ).

22. Bazylev V.V., Galtseva N.V. Physical rehabilitation of the patients during the early postoperative period after coronary artery bypass surgery. Russian journal of the physical therapy, balneotherapy and rehabilitation. 2016; 3 (15): 124-130 (in Russ).

23. Lubinskaya E.I., Nikolaeva O.B., Zelenskaya I.A., Velikanov A.A., Levashkevich Yu.L., Demchenko E.A. Psychological peculiarities of ischemic heart disease patients, who underwent elective coronary artery bypass surgery, and quality of life dynamics, depending on participation in program of cardiac rehabilitation. Preventative and clinical medicine. $2012 ; 4(45): 66-70$.

24. Ganenko O.S., Kytyzova A.E., Nazimova M.V., Demchenko E.A. Bezopasnost I effectivnost rannih trenagernih trenirovok bolnih iscemicheskoi boleznyu serdtsa posle koronarnogo shuntirovaniya. Cardiosomatica. 2013; 1: 21-22 (in Russ).

25. Pomeshkina S.A., Borovik I.V., Sergeyeva T.Yu., Sizova I.N., Golovkin A.S., Barbarash O.L. The vasoprotective activity of early physical trainings

in patients undergoing coronary artery bypass surgery. Cardiosomatica. 2012; 2: 15-19 (in Russ).

26. Kuular A.M., Kakuchaya T.T., Dgitava T.G., Tokaeva Z.K., Pachuashvili N.V. Vliyanie ergometricheskih nagruzok na laktatnyu sistemy energoobespechenia u kardiohirurgicheskih bolnih. Bulleten NCSSH im. A.N. Bakyleva RAMN serdechno-sosydistie zabolevaniya. 2016; 3 (17): 136-141 (in Russ).

27. Pomeshkina S.A., Borovik I.V., Krupyanko E.V., Zavyrylina I.N., Barbarash O.L. Compliance to non-drug therapy in patients with coronary artery disease underwent coronary artery bypass grafting. Aterosclerosis. 2013; 1: 29-35 (in Russ).

28. Boshoyan A.A., Malikov V.E. Rol phizioterapevticheskogo lecheniya I lechebnoi fizkulturi $\mathrm{v}$ rannem periode $\mathrm{u}$ bolnih posle kardiohirurgicheskih vmeshatelstv. CardioСоматика. 2013; 1: 13-14 (in Russ).

29. Spiroski D., Andjic M., Stojanovic O.I., Lazovic M., Dikic A.D., Ostojic M. et al. Very short/short-term benefit of inpatient/outpatient cardiac rehabilitation programs after coronary artery bypass grafting surgery. Clin Cardiol. 2017; 40(5): 281-286.

30. Argunova Y.A., Trubnikova O.A., Mamontova A.S., Syrova I.D., Kuhareva I.N., Maleva O.V., Barbarash O.L. The influence of threeweek aerobic exercise program on neurodynamic parameters of patients underwent coronary bypass grafting. Russian Journal of Cardiology. 2016;(2):30-36. (In Russ.) DOI:10.15829/1560-4071-2016-2-30-36

31. Kotseva K., Wood D., De Backer G. De Bacquer D., Pyorala K., Reiner Z. etal.EUROASPIRE Study Group. EUROASPIRE III. Management of cardiovascular risk factors in asymptomatic high-risk patients in general practice: cross-sectional survey in 12 European countries. EurJ CardiovascPrevRehabil. 2010; 17: 530-535.

\section{Для корреспонденции:}

Иноземцева Анастасия Анатольевна

Адрес: 650002, г. Кемерово, Сосновый бульвар, д. 6

Teл.+7-905-969-95-11, e-mail: nastya060988@yandex.ru

For correspondence:

Inozemtseva Anastasia

Address: 6, Sosnoviy blvd., Kemerovo, 650002, Russian Federation Tel.+7-905-969-95-11, e-mail: nastya060988@yandex.ru 